\title{
STANDARDISED ECHOGRAPHY IN THE DIFFERENTIAL DIAGNOSIS OF EXTRAOCULAR MUSCLE ENLARGEMENT
}

\author{
A. D. DICK, V. NANGIA and H. ATTA \\ Aberdeen
}

\begin{abstract}
SUMMARY
Standardised echography is well documented for its use in the evaluation of enlarged extraocular muscles in orbital disease, but is still a largely underdeveloped imaging method in Britain. This paper demonstrates the technique of muscle ultrasound scanning and the characteristic echographic findings in a variety of extraocular muscle diseases, as illustrated by five case reports. The role of echography in the management of such cases is discussed.
\end{abstract}

Extraocular muscle enlargement is found in many orbital diseases. Enlargement may be the primary event as seen in thyroid orbitopathy or myositis. Orbital venous congestion, from whatever cause, will also give rise to a secondary swelling of all the extraocular muscles. Differentiation of the causes of muscle enlargement is not always apparent clinically, and further imaging techniques are often employed in order to make the diagnosis.

An orbital imaging technique that detects early muscle enlargement and allows differentiation of 'tissue types' of swelling is likely to be of value in the diagnosis and management of orbital disease. Standardised echography is a safe and cost-effective method of diagnostic imaging that fulfils the above requirements. This technique, developed by Ossoinig, ${ }^{1,2}$ requires specific instruments and examination methods. ${ }^{3,4}$ Its value in the diagnosis of many orbital diseases has been well documented. ${ }^{5-9}$

This paper presents a compilation of case reports illustrating the usefulness of standardised echography in the differential diagnosis of extraocular muscle disorders. Techniques of muscle scanning are also briefly described.

\section{METHODS}

The cases reported were selected from 78 abnormal

Correspondence to: Mr A. D. Dick, MRCP, FRCS, FCOphth, Department of Ophthalmology, Medical School, Foresterhill, Aberdeen AB9 2ZD, UK. muscle studies out of a total of 287 orbital ultrasound examinations carried out in the eye department of Aberdeen Royal Infirmary during a 3-year period from 1989 to 1991.

Examinations were performed as previously described. $^{1-3}$ Instruments used were the Ophthascan-S combined standardised A- and B-scan; more recently, the Ophthascan mini-A was utilised. The A-scan measures the thickness of the four recti muscles and enables the echographer to 'tissue differentiate' types of swelling. Biometry findings were compared with the normal range of figures obtained by one of the authors. ${ }^{10}$ B-scan echography presents a topographical and semi-quantitative assessment of the muscles. Both modes were also used to assess the presence of concomitant optic nerve disease, posterior scleritis, engorgement of orbital veins, and presence of any orbital mass lesion. Occasionally Doppler ultrasound was employed to detect any increase in orbital blood flow in cases of orbital venous congestion.

\section{Standardised A-Scan (Fig. 1)}

The instrument is set at 'tissue sensitivity'." Topical anaesthetic is installed, and the probe placed directly on the globe opposite the muscle to be scanned. Measurements are taken while the patient fixates in the primary position to eliminate changes in muscle size during contraction and relaxation. Thickness of the insertion is first noted and compared with that of the contralateral fellow muscle. Biometry of the muscle belly is taken at its widest diameter, which is ascertained during dynamic examination. Reflectivity of the muscle is observed and compared with the normal muscle appearance. If other lesions are suspected, scanning of the orbital fat and measurements of the optic nerve are performed.

\section{B-Scan (Fig. 2)}

Both longitudinal and transverse (cross-section) scans are 


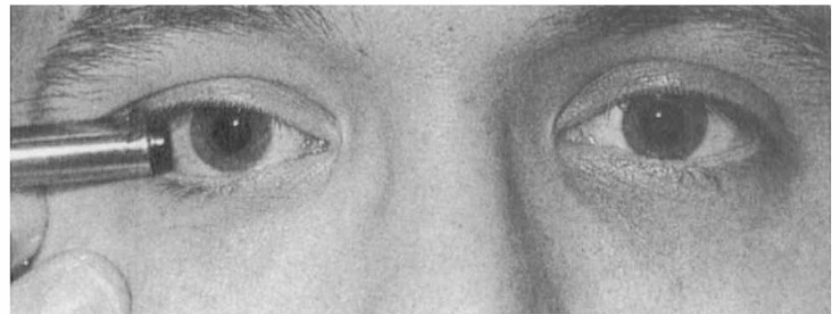

Fig. 1a.

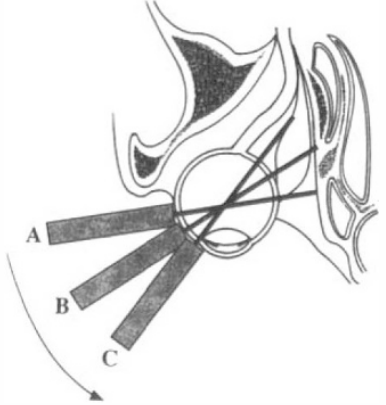

Fig. 1b.
Fig. 1c.

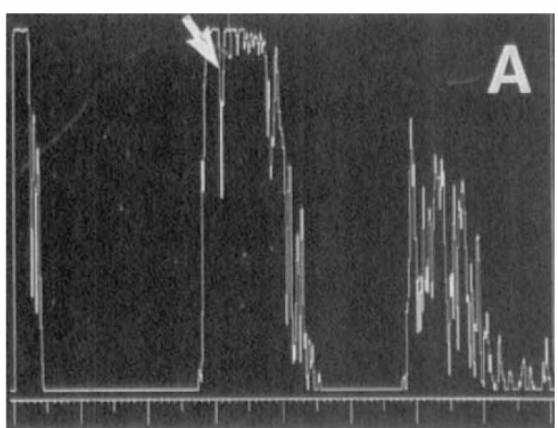

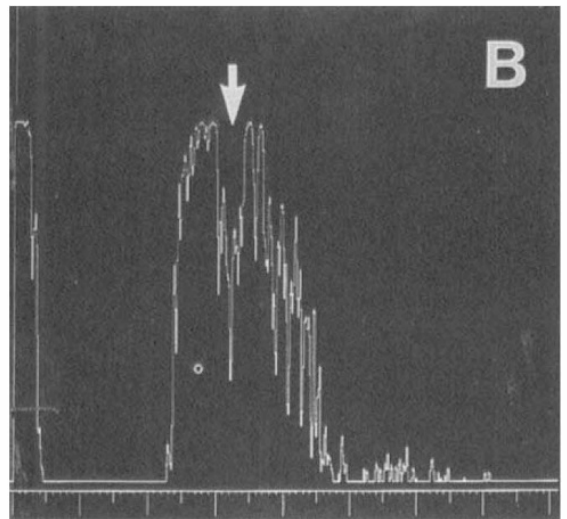

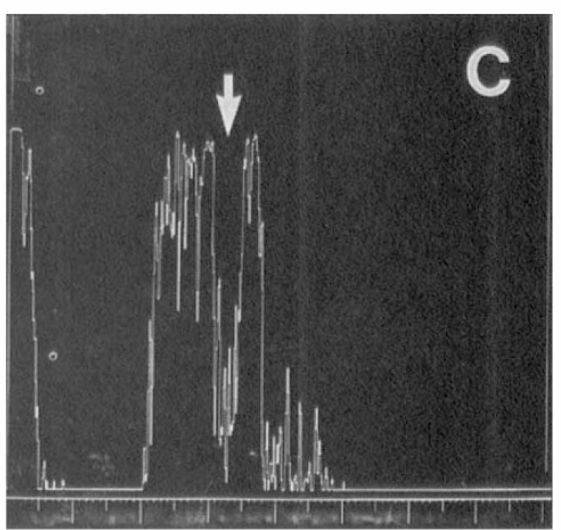

Fig. 1. Standardised A-mode echographic appearance of normal extraocular muscle. The probe is placed on the globe opposite the muscle to be scanned $(a)$. As the beam is swept posteriorly through the muscle length $(b$ and $c)$ the muscle insertion $(A)$ is detected as a thin defect in the echographic trace followed by wider defects in the mid muscle belly $(B)$ and posterior aspect of the muscle $(C)$. The normal muscle appearance consists of a group of medium reflective spikes separated from the surrounding fat pattern by two tall spikes representing the highly reflective muscle sheaths (white arrows).

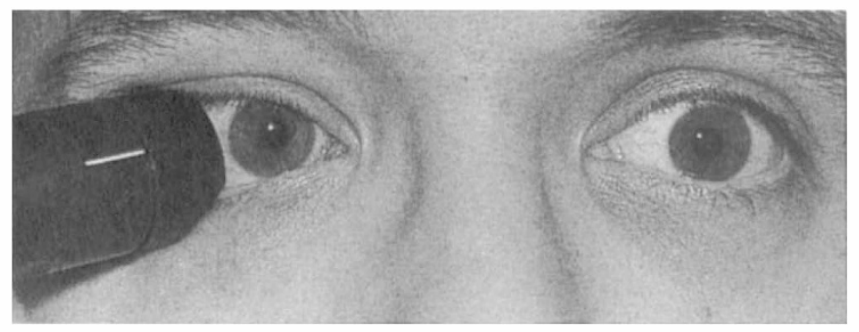

Fig. 2a.

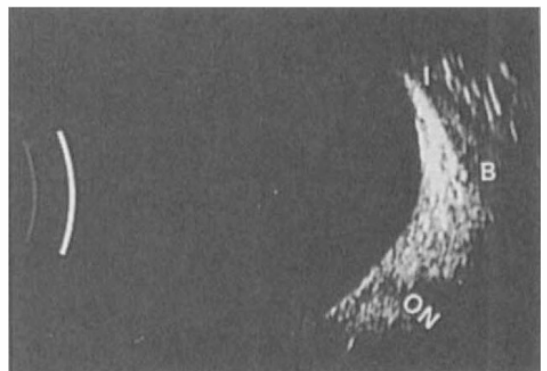

Fig. 2 b.
Fig. 2c.
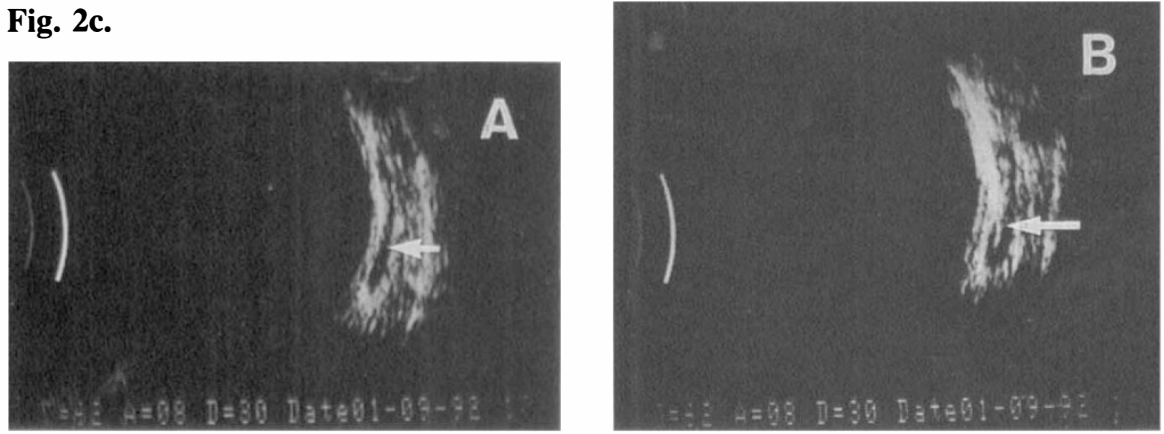

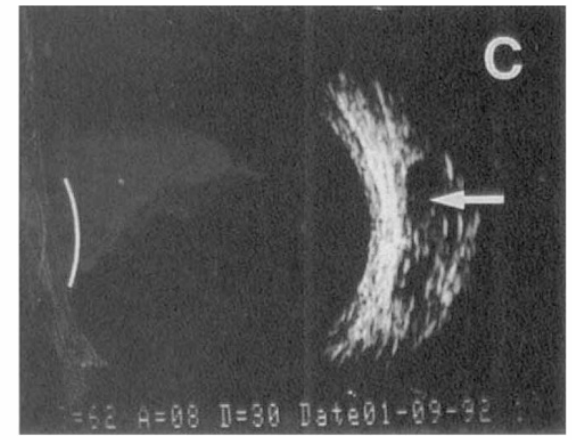

Fig. 2. Normal B-mode echographic appearance of extraocular muscle. The probe is placed directly on the globe opposite the muscle to be scanned $(a)$. (b) A longitudinal section through the muscle. I, insertion; B, belly of muscle; ON, optic nerve. (c) Cross-sections of the muscle ( $A, B, C$ corresponding to sections of muscles scanned in Fig. 1). The muscle (arrows) appears as a darker outline compared with the highly reflective orbital fat. 


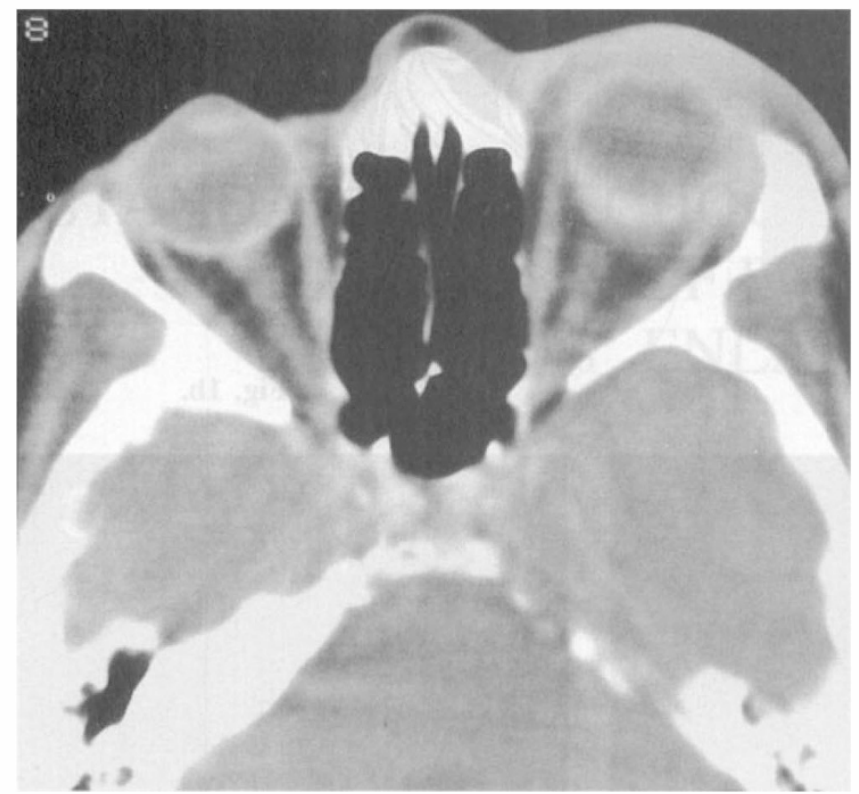

Fig. 3. (Case 1) CT scan of the orbits. The CT scan demonstrates proptosis of the right eye with increased density of the soft tissues within the orbit, particularly the posterior aspect of the globe. The horizontal recti appear not to be enlarged.

obtained of the four recti. As in the A-scan the probe is placed directly on the globe to improve resolution and observe eye gaze during the procedure. By maintaining the same decibel gain, and grey scale, a semi-quantitative assessment and comparison of muscle size between the two eyes is obtained. Further scanning of the orbit and optic nerve are performed as required. B-scanning was particularly useful in detecting enlarged orbital veins.

\section{CASE REPORTS}

Case 1: Orbital Myositis

A 50-year-old man presented with a history of an 'inflamed' right eye and on examination had episcleral and conjunctival congestion with limitation of ocular movements. Visual acuity and colour vision were normal. The X-ray appearance suggested a sinusitis, with mucosal thickening, and the CT scan was further suggestive of a 'secondary orbital inflammation' (Fig. 3). He was treated initially with antibiotics but with no improvement. Subsequent echography demonstrated significant enlargement of the superior rectus/levator complex. The muscle was of low internal reflectivity and there was associated chorioretinal thickening and surrounding orbital tissue oedema (Fig. 4). The lateral rectus was also thickened. These echographic findings were suggestive of a severe myositis. With steroid treatment his symptoms improved dramatically, with a concomitant reduction in muscle size and normalisation of internal reflectivity on A-scan (Fig. 5).

\section{Case 2: Thyroid Orbitopathy}

A 59-year-old woman presented with a 6-month history of an intermittent red left eye, and the feeling that her left eye was larger. Visual acuity was unimpaired. Exophthalmometry was 22 right, and 25 left. Ocular movements were full. She was biochemically hyperthyroid and was therefore treated with radioactive iodine. The following year she developed an acutely red and chemotic left eye with a slight drop in her vision. Visual acuity was 6/12 both eyes and her Ishihara plate reading was diminished,
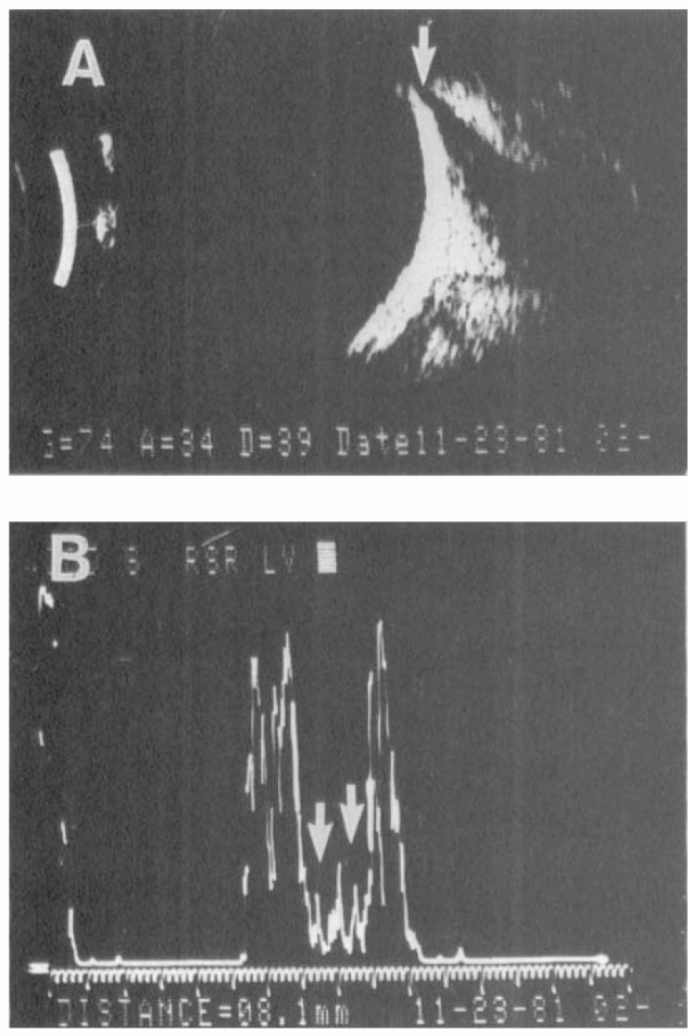

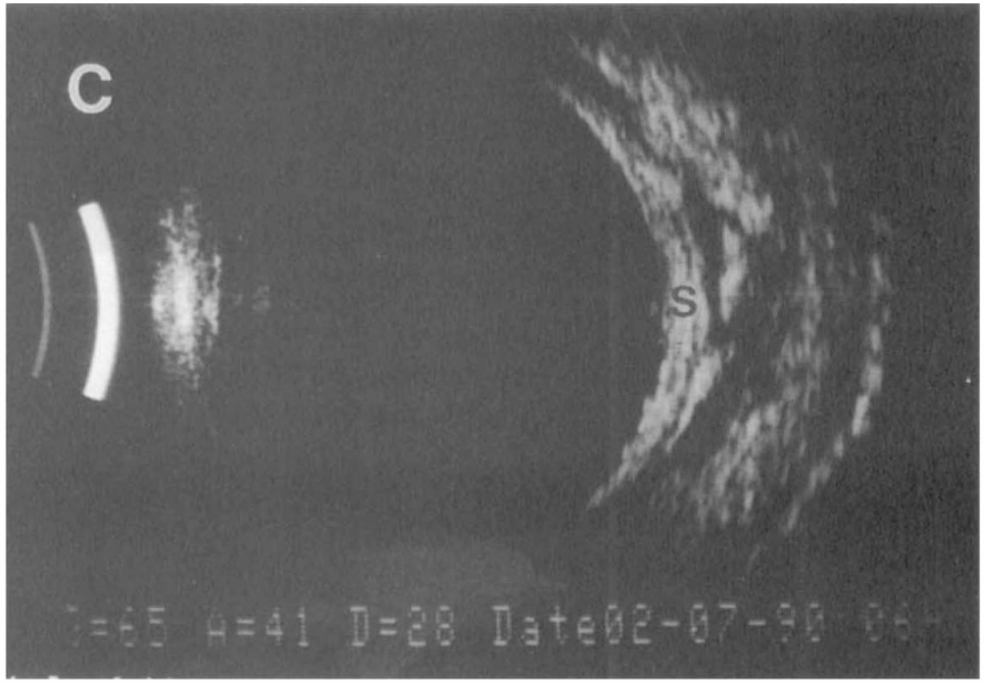

Fig. 4. (Case 1) A- and B-mode echography of the right superior rectus. (a) The right superior rectus is enlarged $(A)$, particularly at the insertion of the muscle (arrow). The internal reflectivity on A-scan is markedly reduced, consistent with myositis $(B)$. The B-mode echograph $(C)$ demonstrates episcleral thickening and oedema of surrounding orbital tissue, as was seen on the CT scan, consistent with an associated scleritis $(S)$. 

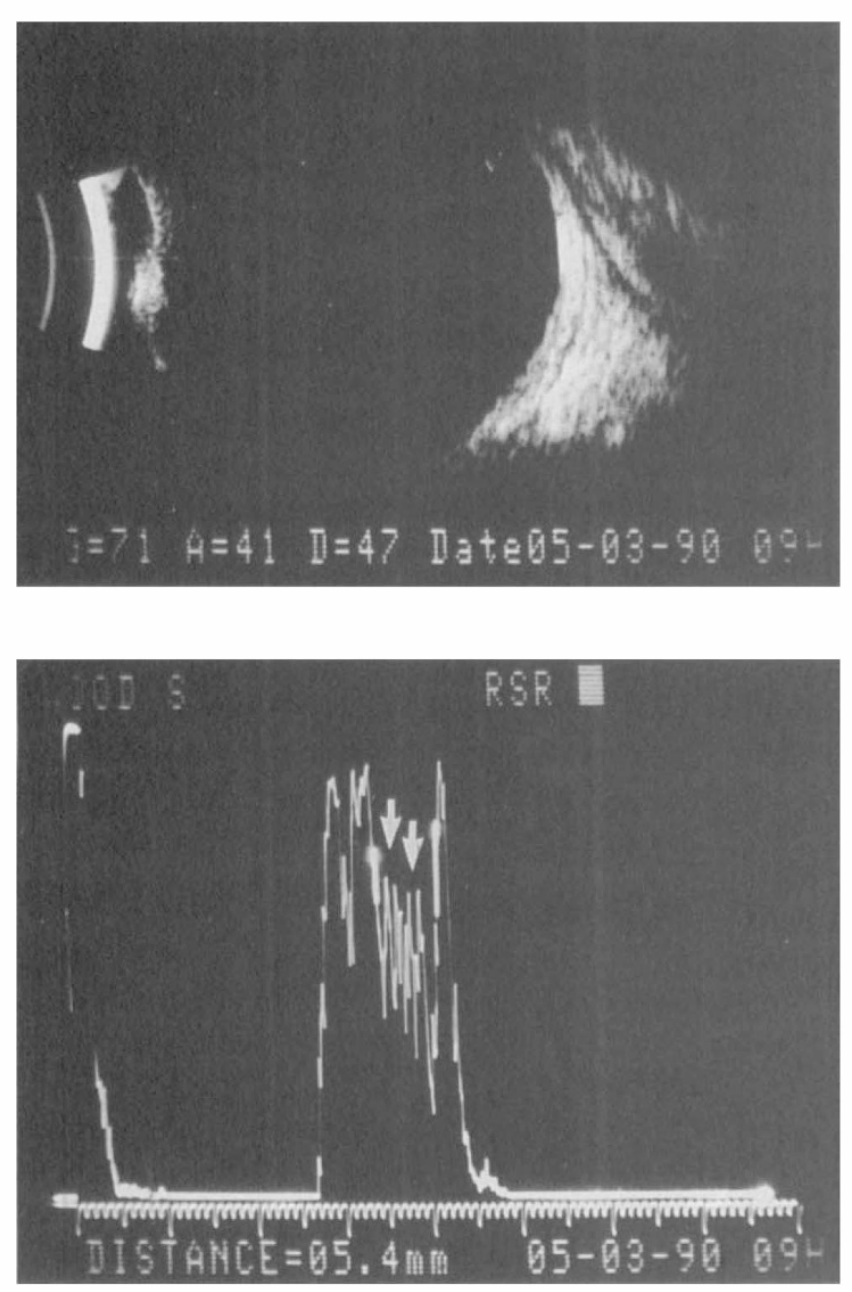

Fig. 5. (Case 1) A- and B-mode echography of right superior rectus after steroid treatment. There is a reduction in muscle size. The internal reflectivity on the A-scan has returned to normal levels (arrows).

but no afferent pupillary defect was noted. There was no change in exophthalmometry readings at the time of echography. Orbital echography demonstrated enlargement of all extraocular muscles, especially the left inferior and medial rectus. Reflectivity was normal (medium height) (Fig. 6). There was evidence of orbital venous congestion by the presence of an enlarged orbital vein on B-scan of the left eye. The muscle bellies were swollen to the orbital apex and optic nerve measurements demonstrated a swollen left optic nerve $(3.7 \mathrm{~mm}$ in primary position and 2.7 $\mathrm{mm}$ at $30^{\circ}$ of abduction), which is consistent with acute optic nerve sheath thickening in Graves' ophthalmopathy. Optic nerve scanning has been described previously by one of the authors. ${ }^{12}$

\section{Case 3: Lithium Orbitopathy}

This 76-year-old woman presented with a history of persistent chemosis. She was otherwise well except for a seasonal affective disorder for which she was taking lithium. Echography demonstrated uniform enlargement of the extraocular muscles, maximal at the muscle belly, with medium to medium-high reflectivity (Fig. 7). There was no evidence of any orbital apex lesion, which was confirmed by CT imaging. She had a raised level of thyroid stimulating hormone, but normal thyroxine levels and no thyroid autoantibodies were detectable, consistent with lithium therapy. A diagnosis of lithium-induced orbitopathy was made (there was no other clinical evidence of Graves' disease), and the muscle thickness and chemosis returned to normal after cessation of lithium therapy.

\section{Case 4: Orbital Apex Syndrome}

A 46-year-old man presented with a 48-hour history of a painful red left eye. On examination his visual acuity and colour vision was unaffected. There was no relative afferent pupillary defect. All pursuit movements were severely restricted and the conjunctiva was engorged. CT scanning was suggestive of sinusitis with thickened mucosae (Fig. 8). He was treated initially with antibiotics but without any improvement. Ultrasonography was then performed. The recti muscles were all uniformly enlarged with normal reflectivity, and there was an enlarged orbital vein consistent with secondary orbital venous congestion (Fig. 8). The optic nerve was also enlarged on echography, with a positive $30^{\circ}$ test (as described in case 2 ), suggestive of a fluid-filled optic nerve sheath. These echographic changes were consistent with an inflammatory orbital apex syndrome (Tolosa-Hunt). Steroids were thus intro-
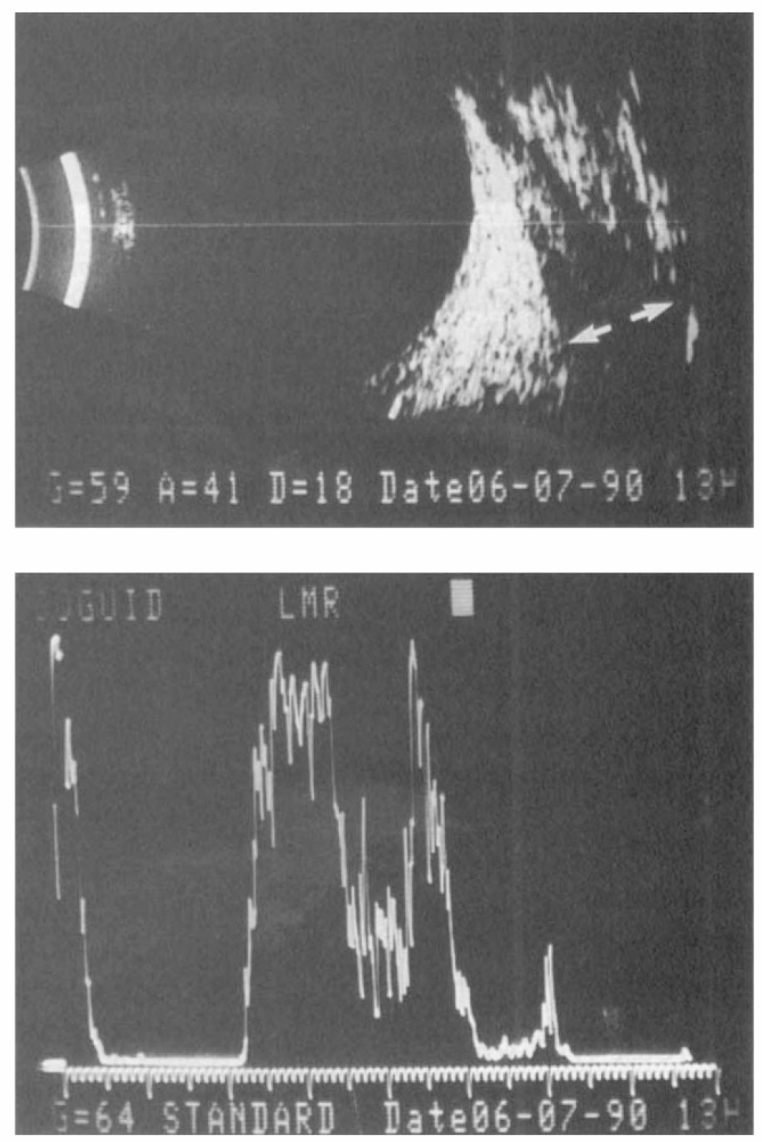

Fig. 6. (Case 2) A-mode and longitudinal B-mode echography of enlarged left medial rectus. The left medial rectus is enlarged particularly at the muscle belly (two arrows) with normal muscle reflectivity on A-scan. The muscle insertion is spared. 

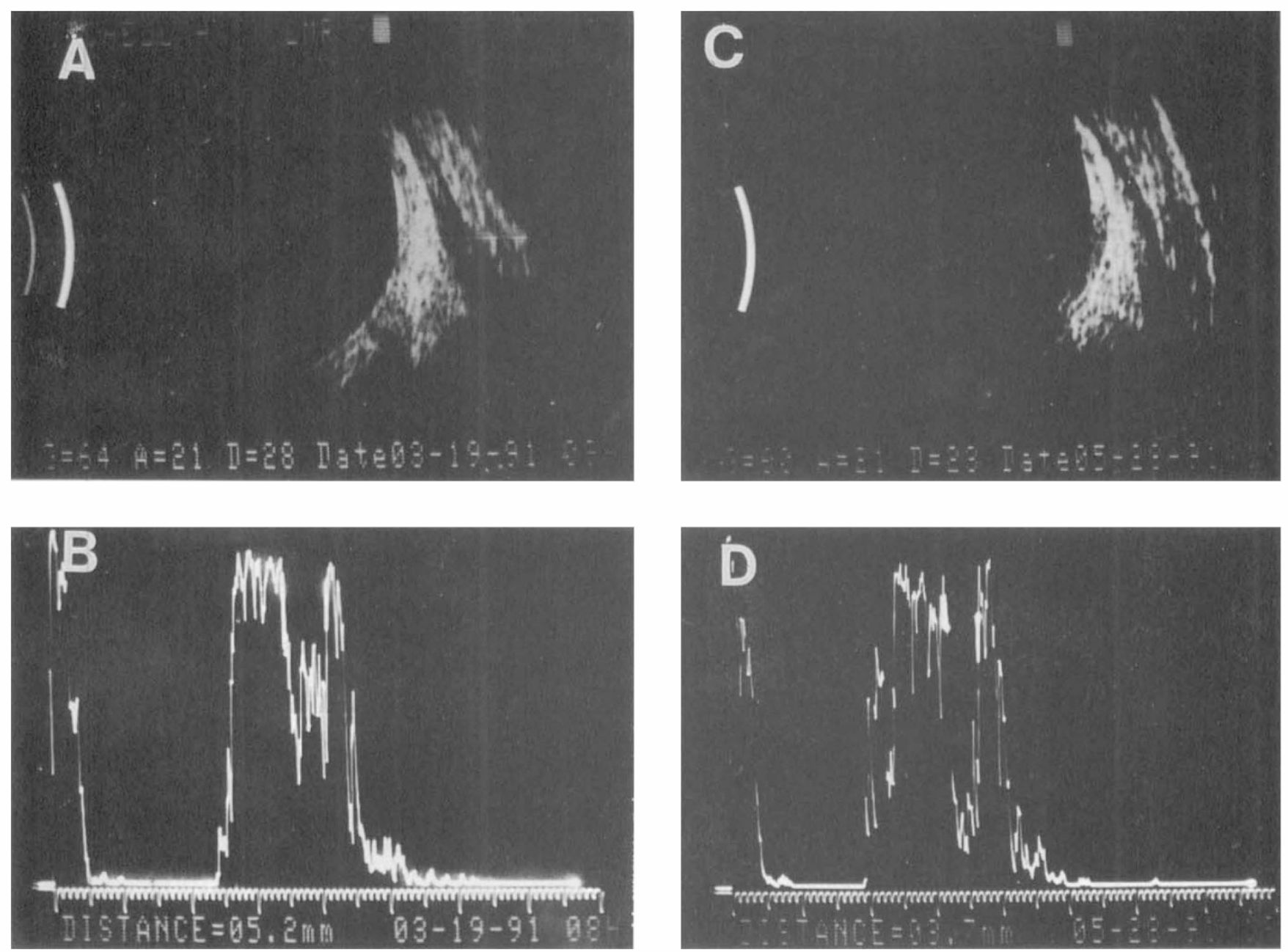

Fig. 7. (Case 3) A-and B-mode echography of left medial rectus. The medial rectus belly is enlarged (5.2 mm) with normal reflectivity on $A$-scan $(A$ and $B)$. The diameter reduced to $3.7 \mathrm{~mm}$ after stopping lithium treatment $(C$ and $D)$. (From Dick et al. Lithium-induced orbitopathy. Arch Ophthalmol 1992, 110: 452-3. (C) 1992 AMA.)

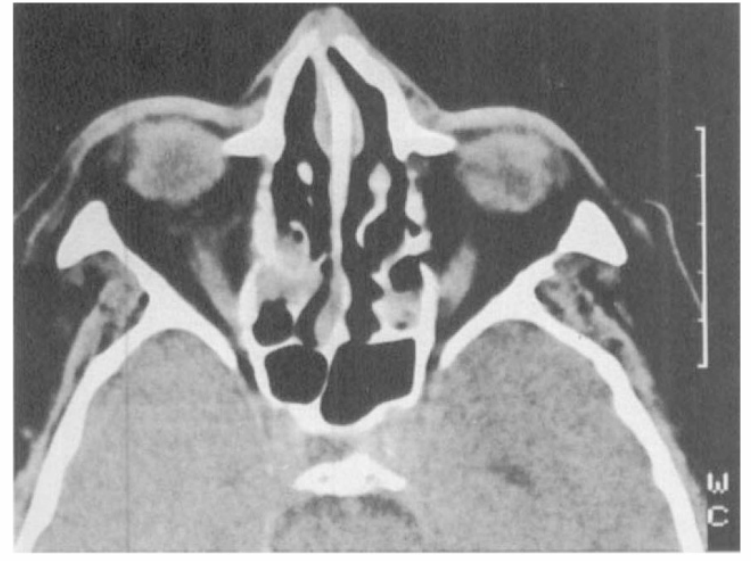

Fig. 8. (Case 4) CT scan of paranasal air sinuses and $A$ - and B-mode echography of orbits. The CT scan demonstrates mucosal thickening of the air sinuses with no reported swelling of muscles or optic nerve. Normal $B$ - and A-mode scans of right orbit are seen ( $A$ and $B$ ) and an enlarged orbital vein $(C$, arrow) and mild thickening of left medial rectus on A-scan (D) are demonstrated in the left orbit.
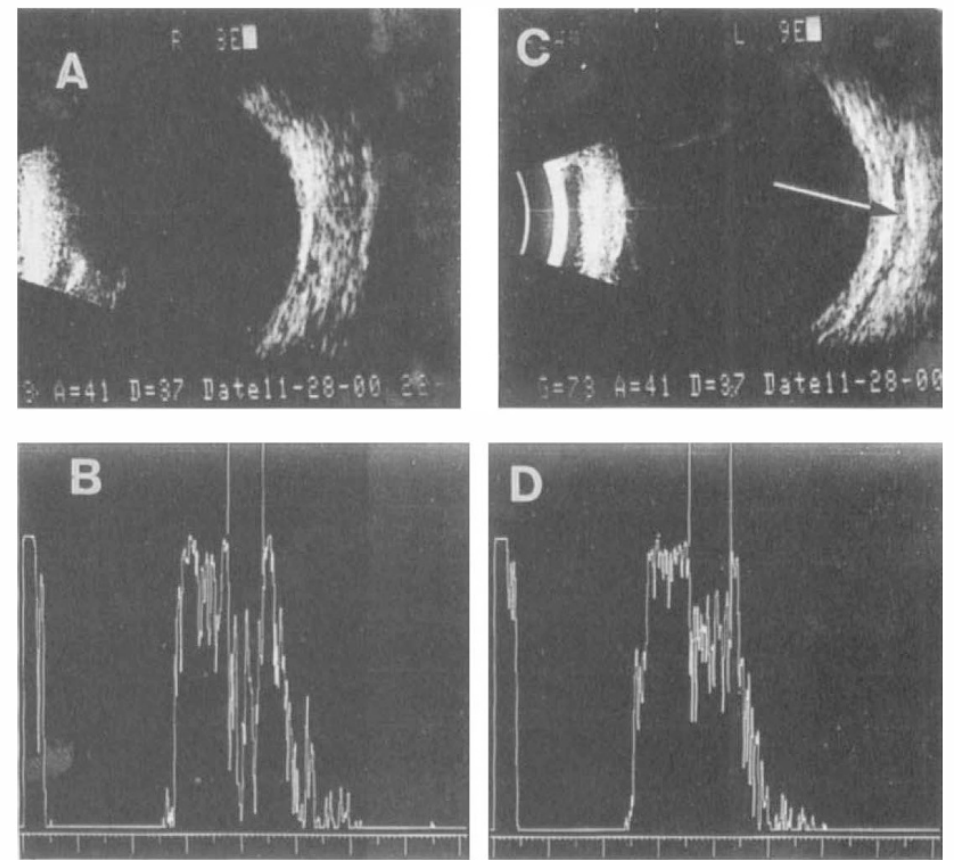

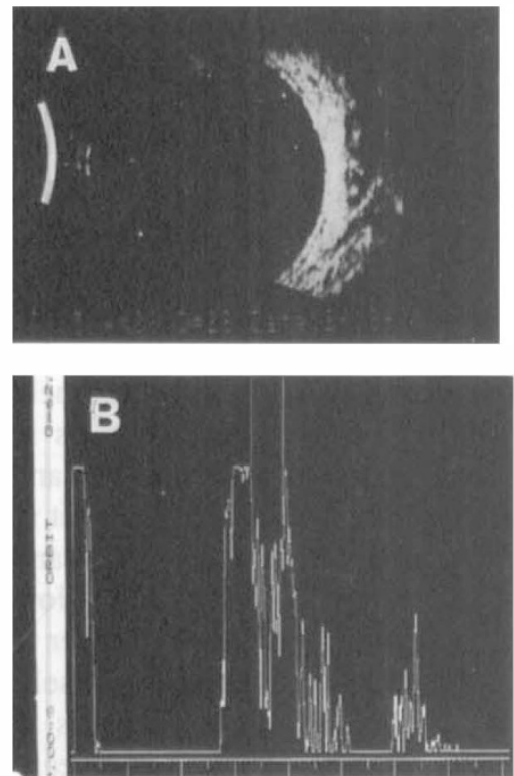
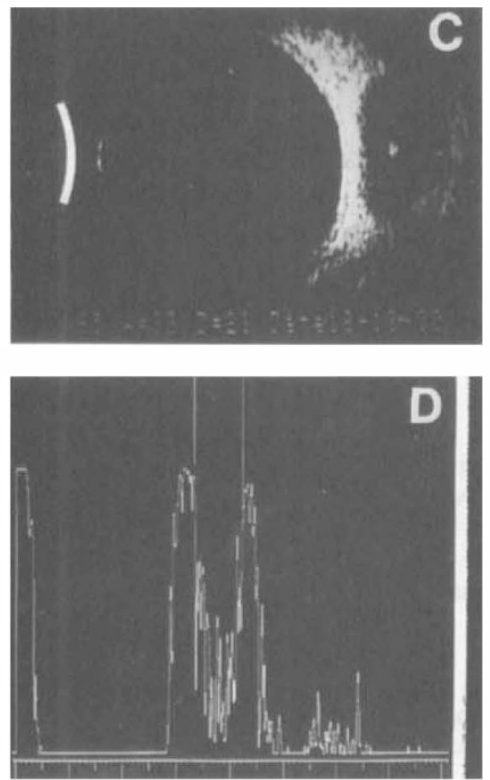

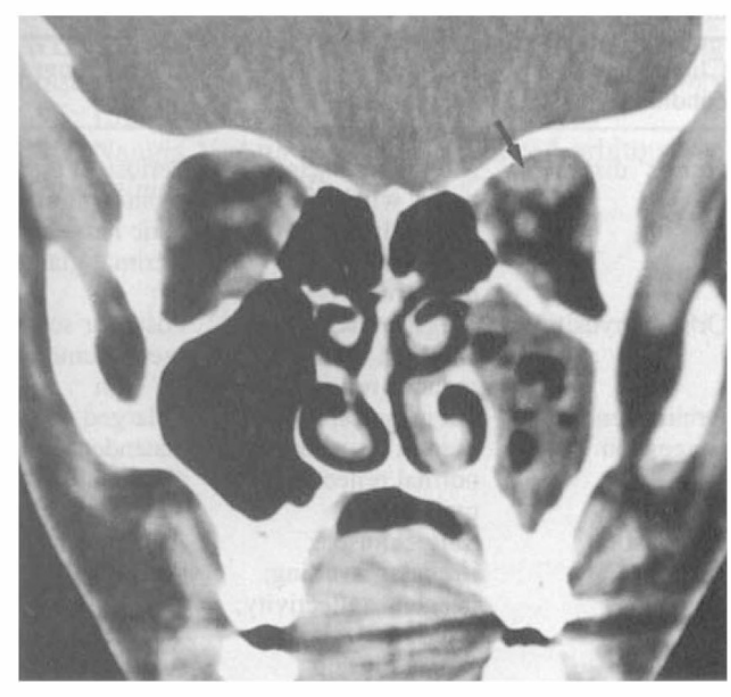

Fig. 9. (Case 5) A-mode and transverse B-mode echography of right and left superior recti and CT of paranasal air sinuses. The left superior rectus is uniformly enlarged $(C$ and $D)$ with normal muscle reflectivity compared with right superior rectus $(A$ and $B)$. The $C T$ scan demonstrates marked opacification and mucosal thickening of the left paranasal air sinuses and an enlarged superior rectus (arrow).

duced with a subsequent rapid normalisation of the clinical signs.

\section{Case 5: Pansinusitis}

An 18-year-old man presented with a 2-day history of left ocular pain and diplopia. His vision was unaffected. He had a marked hypotropia and restriction of elevation and depression of his left eye. There was $2 \mathrm{~mm}$ of proptosis on the affected side. The conjunctiva was minimally injected, and ocular examination was otherwise unremarkable; in particular no optic nerve abnormality was found. Echography demonstrated a large left superior rectus of normal reflectivity, thus excluding myositis (Fig. 9). CT imaging did provide evidence of a pansinusitis (Fig. 9). Following antral lavage and antibiotics the proptosis and ocular movements returned to normal.

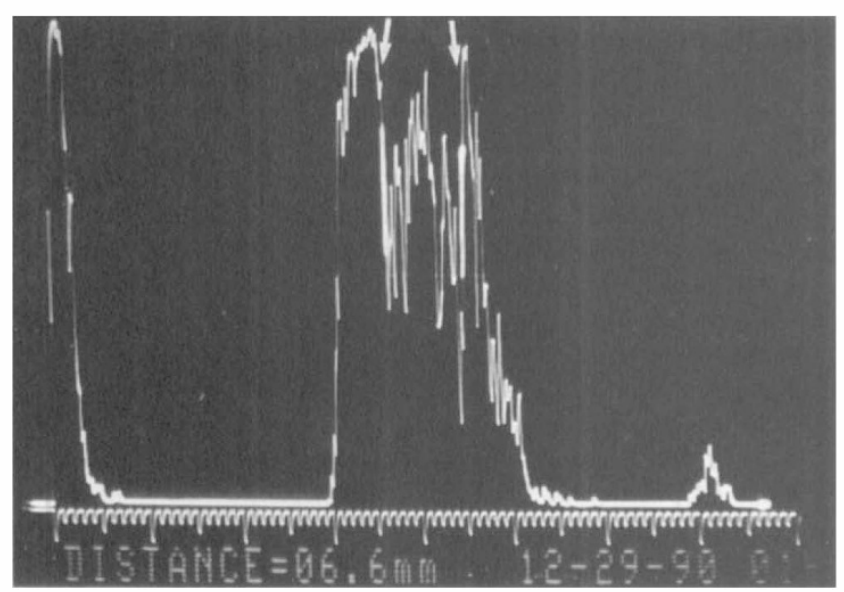

Fig. 10. A-mode echography of recti muscle. The muscle is enlarged, with a diameter of $6.6 \mathrm{~mm}$. The reflectivity is also increased, suggestive of chronic fibrosis of the muscle in longstanding Graves' ophthalmopathy.

\section{DISCUSSION}

During the 3-year period, 78 abnormal muscle studies were recorded, out of a total of 287 cases referred for orbital echographic examinations $(27 \%)$. Although this figure is lower than the $35 \%$ quoted by Ossoinig, ${ }^{13}$ it still represents a significant number of muscle disorders causing signs and symptoms of orbital disease, for which echography was requested. As expected thyroid orbitopathy constituted the commonest cause of enlarged extraocular muscles. ${ }^{13}$ Orbital myositis and other common disorders demonstrated by echography in our unit are listed in Table I.

Thyroid orbitopathy is characterised by the enlargement of several muscles in both orbits, even if only one orbit is clinically involved. Any muscle can be affected. $^{14,15}$ Muscle thickness tends to vary with the chronicity of the disease to a greater degree than can be explained by observer variation. Muscle insertion is normally spared. Enlargement of the muscle is maximal posteriorly in the muscle belly. Reflectivity of the muscle is either normal or increased, especially in the later stages of the disease, when fibrosis ensues (Fig. 10). However, at this stage of the disease scanning may become technically difficult because of the similarity in reflectivity of the fibrotic muscle and surrounding orbital tissue. Other orbital findings in active Graves' ophthalmopathy include widening of the fat pattern and demonstrable orbital veins, which are mainly situated nasally in the orbit. In com-

Table I. Diagnoses made with the aid of standardised echography

\begin{tabular}{lr}
\hline Thyroid orbitopathy & 64 \\
Myositis & 5 \\
Metastases & 4 \\
Congestive orbitopathy & 4 \\
Lymphoma & 1 \\
\hline
\end{tabular}


Table II. Summary of the echographic findings in orbital disease affecting extraocular muscles

\begin{tabular}{|c|c|c|}
\hline $\begin{array}{l}\text { Clinical } \\
\text { condition }\end{array}$ & $\begin{array}{l}\text { Muscle } \\
\text { echography }\end{array}$ & $\begin{array}{l}\text { Other echography } \\
\text { findings }\end{array}$ \\
\hline Graves' disease & $\begin{array}{l}\text { Multiple muscles; } \\
\text { varies with time; } \\
\text { bilateral; } \\
\text { late increase in } \\
\text { reflectivity }\end{array}$ & $\begin{array}{l}\text { Periosteal thickening; } \\
\text { prominent orbital fat; } \\
\text { optic nerve thickening; } \\
\text { lacrimal gland swelling }\end{array}$ \\
\hline Orbital myositis & $\begin{array}{l}\text { Single muscle; } \\
\text { enlarged insertion; } \\
\text { reduced reflectivity }\end{array}$ & $\begin{array}{l}\text { Posterior scleritis; } \\
\text { pseudotumour; } \\
\text { 'T' sign }\end{array}$ \\
\hline $\begin{array}{l}\text { Orbital venous } \\
\text { congestion }\end{array}$ & $\begin{array}{l}\text { All muscles; } \\
\text { normal insertion; } \\
\text { normal reflectivity; } \\
\text { unilateral }\end{array}$ & $\begin{array}{l}\text { Enlarged orbital vein; } \\
\text { distended optic nerve; } \\
\text { abnormal Doppler }\end{array}$ \\
\hline Neoplastic & $\begin{array}{l}\text { Single muscle; } \\
\text { irregular swelling; } \\
\text { irregular reflectivity; } \\
\text { progressive }\end{array}$ & $\begin{array}{l}\text { Adjacent tumour mass; } \\
\text { bony erosion }\end{array}$ \\
\hline $\begin{array}{l}\text { Muscle } \\
\text { haematoma }\end{array}$ & $\begin{array}{l}\text { Single muscle; } \\
\text { low reflectivity; } \\
\text { spontaneous } \\
\text { resolution }\end{array}$ & $\begin{array}{l}\text { Adjacent haematoma or } \\
\text { optic nerve distension }\end{array}$ \\
\hline
\end{tabular}

pressive cases the optic nerve diameter increases, as described in case report. ${ }^{2}$

Orbital myositis is typically a single muscle disorder. All muscles are susceptible however, including the obliques,${ }^{16}$ although this was not found in our study. Prominent swelling of the insertion and the reduced reflectivity of the belly of the muscle (presumably due to the cellular infiltration and oedema) are the most characteristic features. Other findings that may be present are posterior scleritis adjacent to the muscle involved and an inflammatory pseudo-tumour mass. Inflammatory spread to the retrobulbar optic nerve sheath can also be seen in some cases, giving rise to the characteristic ' $T$ ' sign. Systemic steroid therapy produces a profound reduction in muscle size. In our experience and that of others ${ }^{5,13}$ it is advisable to titrate the steroid dose against the resolving echographic appearance, thus preventing unacceptable relapses on reduction of steroid therapy.

Congestive orbital disorders produce 'passive swelling' of all the muscles in the orbit, with no change in reflectivity. One or more of the following abnormalities are usually seen to help confirm the diagnosis. These include an enlarged orbital vein, fluid distension of the optic nerve sheaths, widening of the fat pattern and abnormal Doppler responses of orbital blood flow. Typical examples of such disorders include arterio-venous fistulae in cavernous or dural sinuses, orbital apex or Tolosa Hunt syndrome and middle cranial fossa mass lesions. If suspected, computerised tomography or magnetic resonance imaging techniques must be employed for a full assessment to be obtained.

In the majority of patients, echography alone was sufficient in reaching the diagnosis. When other diagnostic features were absent echography isolated the muscle(s) involved and directed the clinician to further investigations or imaging methods in order to obtain a diagnosis. CT scanning was employed to demonstrate suspected intracranial lesions associated with orbital disease and to confirm the presence of paranasal air sinus infections. In some cases, however, CT scanning failed to highlight the enlarged muscles and in addition failed to demonstrate other echographic findings such as engorged orbital vein, thickening of the retinochoroidal layer, posterior scleritis and optic nerve swelling. Table II summarises the echographic features of the common causes of enlarged extraocular muscles.

To conclude, standardised echography is an extremely useful diagnostic tool for establishing the diagnosis in extraocular muscle disease. It also provides a safe and cost-effective means of serial examination of the orbit in thyroid orbitopathy, in order to assess disease progress and the presence of any concomitant optic nerve compression. In orbital myositis, serial assessments are used in order to titrate the steroid dose. As an imaging technique by itself, echography is adequate for establishing a diagnosis in many cases and may also be used as a method of screening, obviating the need for other, more expensive imaging techniques.

Key words: Extraocular muscles, Graves' ophthalmopathy, Orbital myositis, Standardised echography.

\section{REFERENCES}

1. Ossoinig KC: Standardised echography: basic principles, clinical applications, and results. Int Ophthalmol Clin 1979, 19(4): 127-210.

2. Ossoinig KC: Echography of the eye, orbit and periorbital region. In: Arger PH, ed. Orbit Roentgenology. New York: Wiley, 1977: 224-69.

3. Byrne SF: Standardised echography of the eye and orbit. Neuroradiology 1986, 28: 618-40.

4. Atta HR: Techniques and application of diagnostic ultrasound. In: Easty DL, ed. Current Ophthalmic Surgery. Eastbourne: Bailliere Tindall, 1990: 31-46.

5. Byrne SF, Glaser JS: Orbital tissue differentiation with standardised echography. Ophthalmology 1983, 90: 1071-90.

6. Hodes BL, Wienberg P: A combined approach for the diagnosis of orbital disease. Arch Ophthalmol 1977, 95: 781-8.

7. Byrne SF: Evaluation of the optic nerve with standardised echography. In: Smith JL, ed. Neuro-ophthalmology Now. 1986: 45-66.

8. Ossoinig KC: Echographic differentiation of vascular tumours in the orbit. In: Thijssen JM and Verbeek AM, eds. Docum. Ophthal. Proc. Series, vol 29. The Hague: W. Junk, 1981: 283-91.

9. Balchunas WR, Quencer RM, Byrne SF: Lacrimal gland and fossa masses: evaluation by computerised tomography and A-mode echography. Radiology 1983, 149: 751-8.

10. Byrne SF, Gendron K, Glaser JS, Fever W, Atta HR: Diameter of normal extraocular recti muscles with echography. Am J Ophthalmol 1991, 112: 706-13.

11. Till P. Solid tissue model for the standardisation of the echoophthalmograph 7200 MA (Kretztechnik). Doc Ophthalmol 1976, 41: 205.

12. Atta $\mathrm{H}$ : Imaging of the optic nerve with standardised echography. Eye 1988, 2: 358-66.

13. Ossoinig $\mathrm{KC}$, Hermsen VM: Myositis of extraocular muscles diagnosed with standardized echography. In: Hill- 
man JS and Lemay MM, eds. Docum Ophthalmol Proc Series, vol 31. The Hague: W. Junk, 1983: 381-92.

14. Ossoinig KC. Ultrasonic diagnosis of Graves' ophthalmopathy. In: Gorman CA, ed. The Eye and Orbit in Thyroid Disease. New York: Raven Press, 1984: 185-211.

15. Atta HR, McCreath G, McKillop JH, Forrester JV, Thomson R, Wilson R, Gray HW: Ophthalmopathy in early thy- rotoxicosis: relationship to thyroid receptor antibodies and effects of treatment. Scot Med J 1990; 35: 41-4.

16. Wan WL, Cano MR, Green RL: Orbital myositis involving the oblique muscles: an echographic study. Ophthalmology 1988, 95: 1522-8.

17. Dick AD, Nangia V, Atta H: Lithium induced orbitopathy. Arch Ophthalmol 1992, 110: 452-3. 